Document downloaded from:

http://hdl.handle.net/10251/60093

This paper must be cited as:

Rojas, J.; Contero, M.; Bartomeu, N.; Guixeres Provinciale, J. (2015). Using Combined Bipolar Semantic Scales and Eye-Tracking Metrics to Compare Consumer Perception of Real and Virtual Bottles. Packaging Technology and Science. 28(12):1047-1056. doi:10.1002/pts.2178.

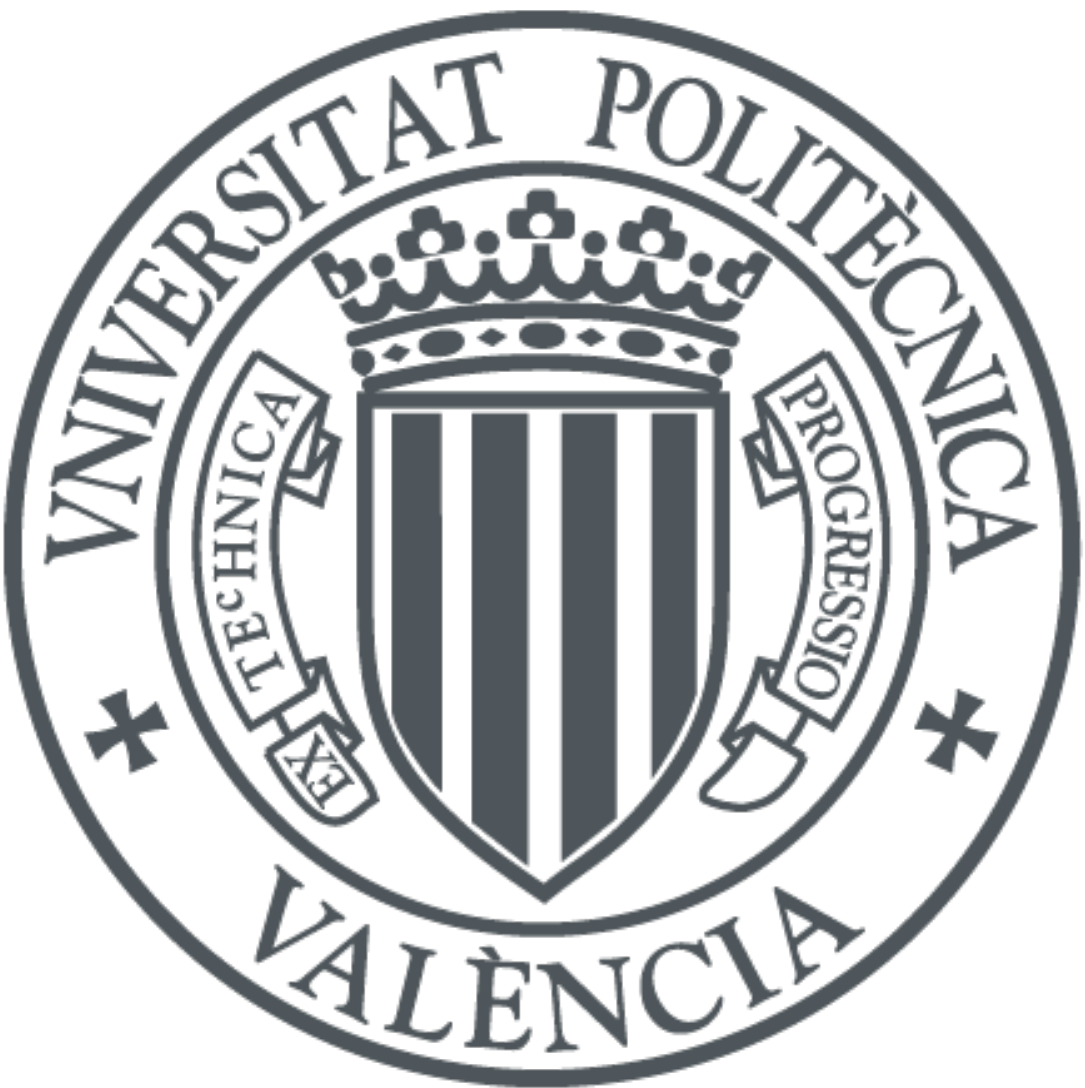

The final publication is available at http://dx.doi.org/10.1002/pts.2178

Copyright Wiley

Additional Information 


\title{
Using Combined Bipolar Semantic Scales and Eye Tracking Metrics to Compare Consumer Perception of Real and Virtual Bottles
}

\author{
By Juan-Carlos Rojas, Manuel Contero, Noemí Bartomeu and Jaime Guixeres \\ I3BH - Instituto Labhuman. Universitat Politècnica de València, Camino de Vera s/n, Valencia, 46022, Spain
}

\begin{abstract}
Use of 3D virtual representations has become a common tool to improve the design process, supporting approaches such as the model-based engineering paradigm. However, there is a limited number of studies related to the perceptual evaluation of virtual products and their packaging comparing both virtual and real representations. This work presents a study with 38 participants about comparing consumer perception of a real and a virtual representation of a beer bottle. Evaluation was carried out applying a bipolar semantic scale based on 4 axes: novelty, resolution, style and emotion. Eye-tracking metrics were used to analyse participant gaze behaviour during the visualization of the stimuli. Virtual stimuli were created using the videogame engine Unity. Although they provide a good graphics quality, they are not an ultrarealistic virtual version of the real bottles. They were created to provide real time interaction in a virtual environment, and this introduces some constraints about render quality. Results show that this medium render quality modifies the consumer perception regarding their response using semantic scales. Eye-tracking analysis also confirms that stimuli orientation affects consumer perception. Some points of view provide similar eye tracking metrics, and other orientations show different results.
\end{abstract}

KEY WORDS: eye-tracking, semantic scales, time fixation, packaging design, virtuality.

\section{INTRODUCTION AND RELATED WORK}

Object visualization is a key aspect to obtain information for understanding product function, value and purpose. Focusing in packaging and product shape as important tools to capture consumers' attention ${ }^{1}$, a growing body of empirical research has started to centre on the influence of the sensory characteristics of these elements using eye-tracking techniques. ${ }^{2,3,4}$

Following this approach, disciplines as "neuromarketing" or "consumer neuroscience" are combining knowledge from neurology and research in consumer behaviour by applying neuroscientific methods to marketing relevant problems. ${ }^{5}$ In this context, neuro-disciplines help to understand how consumers judge the aesthetics and perception of objects ${ }^{6}$ and their packaging, helping to improve the communication of brand's values, enhancing consumer's experience and creating emotional connections with them.

This work seeks to combine the application of eye-tracking technology and semantic scales, in order to compare the conscious and unconscious perception of both virtual and real bottle representations. In beverage marketing, packaging gives an important added value; aesthetics plays an important role in product differentiation and regardless of the consumption domain, ${ }^{7}$ it seems to be a positive factor to trigger some specific responses in consumers such as an immediate desire to buy. ${ }^{8}$

Eye-tracking (ET) is a powerful technique to understand attention. Eye movement provide an objective indicator of where a person's overt attention (and usually also their covert) is focused. ${ }^{9,}{ }^{10}$ This method serves to filter visual information and potentially help to organize it. As a consequence, several parameters of oculomotor behaviour (e.g., saccadic eye movements) are nowadays frequently used; in particular, the locus of an observer's visual fixations is perhaps the single most commonly used parameter when it comes to assessing where a consumer's attention might be focused. ${ }^{11}$ Fixations are defined as gaze patterns in which the eyes are 
relatively immobile, and during which the visual system is assumed to be gathering information. ${ }^{12}$ Eye tracking measures can provide an objective and continuous measure of the user's reactions through eye movement and gaze. ${ }^{13}$

Semantic scales (SC) have become an important instrument in aesthetic evaluation of products, packaging or labels. The work based in psychological studies by Osgood, Suci \& Tannenbaum, ${ }^{14}$ started a serial of studies dedicated to evaluate design in objects. In the last decade, SC techniques have been used in combination of new methods. In this context, the Creative Product Semantic Scale (CPSS) ${ }^{15}$ is an assessment instrument based on a theoretical model that provides a way of understanding creativity in products using novelty, resolution and style as semantic axes. In this paper will notice the use of CPSS, adding an emotional axis for a more complete assessment.

Several previous studies have focused on analysing goal-oriented attention ${ }^{11,16}$ looking at packaging elements like colour, shape, etc. Other studies were centred on examining stimulus-driven attention like messages and labels. ${ }^{17}$ This work complement previous works using a combination of semantic scales and eye tracking to evaluate consumers' perception.

Virtual digital mock-ups provide a very interesting framework to experiment with new design alternatives. However, we must guarantee that the perceptual evaluation that is obtained using virtual prototypes is very similar to the response that is obtained using stimuli based on the real product. Working with real time interactive systems usually requires using medium quality renderings to support high frame rates. This work provides experimental results regarding the feasibility to substitute product stimuli based on real images by other based on medium quality renders, and confirms previous findings ${ }^{18}$ in other contexts, where impact of the limitations in quality of the used virtual stimuli were reported. A case study on the comparison of both rendered and real images used as stimuli to analyse consumer perception of a beer bottle is reported in the next sections.

\section{MATERIALS AND METHODS}

\section{Participants}

This study was conducted with 38 Spanish participants (21 female, 17 male) with ages ranging from 22 to 53 years $(\mathrm{M}=28.63$ years; $\mathrm{SD}=12.00)$ who participated voluntarily in this study and did not receive any compensation for it. All participants reported normal corrected vision, and no colour-blindness.

\section{Materials and apparatus}

An unobtrusive eye tracker that was capable of recording the position of the eyes at a sampling rate of $300 \mathrm{~Hz}$ (Tobii ${ }^{\circledR}$ TX300, www.tobii.com) was used to assess the participants' visual fixations. This device has a 23" flat HD screen and a sensor bar in the lower part of it. This setup allows participants to make large head movements, and to move freely and naturally in front of the screen. Each participant was seated among 60-70 $\mathrm{cm}$ from the eye-tracker system (Figure 1). Tobii ${ }^{\circledR}$ Studio 3.2.1 software was used to calibrate the eye tracker, to present the stimuli, to record the data, and to extract descriptive statistics.

\section{Stimuli}

For this study two sets of stimuli were used. The first set is composed by studio-quality images where a single bottle is presented on a white background. The second set represents the same image content and background, but it uses a computer render created with UNITY (C software instead of the real object photography. All the images (648x1080 resolutions) were set to equal mean luminance and size. Front and back views of the bottle were used in the study as seen in figure 1 . Additionally other bottle perspectives were prepared $\left(0^{\circ}, 15^{\circ}, 35^{\circ}\right.$ and $60^{\circ}$ ).

\section{PROCEDURE}

This study was designed to compare the two versions (real and virtual) of the same bottle. Therefore, participants had to carry out two tasks that we named A and B. Task A corresponds to the real bottle and task B for virtual bottles. The tasks were randomly presented to the participants; after finishing A or B, the participant took a break doing other activity for 10-15 minutes, and then, participants started with the remaining task. The study was conducted in a quiet room under standard illumination conditions. 
The protocol task begins with a gaze calibration guided by Tobii system. After that, the task is presented in a slide presentation, with a specific time for each frame. General instructions for the task were presented on the screen for 22 seconds. Task content (presented in figure 3) is organized in four clusters. All has the same structure. Cluster one begins with a screen with the text " 5 seconds to begin", then two images are displayed consecutively: front and back views of the bottle. Each image was shown for 3.5 seconds. Immediately, a semantic scale is presented in the screen with three questions (corresponding to one of CPSS axes). Participants had 15 seconds to read and answer vocally the choice number for each question (which is codified in a value from 1 to 7). Finally a one second long white screen break is presented before starting the next cluster. The other clusters used other bottle perspectives. The clusters and questions are randomly selected for each participant.

\section{Scoring}

In order to compare the real bottle and virtual bottle, this study used CPSS to understand conscious perception of bottle semantic elements. For physical aspects, three measures were used to analyse eye-tracking data: time to first fixation, total fixation duration and visit count. From a practical point of view, to use these measures a definition of areas of interest (AOI) is necessary; AOIs selection depends on the stimulus characteristics ${ }^{19}$. Time to first fixation expresses the amount of time, in seconds it took for the first fixation to occur in a given AOI, starting when the stimulus is viewed. Total fixation duration is the total duration, in seconds, of all fixations within a given AOI. A visit occurs when a participant transitions between AOIs.

Four common details in bottle were selected (presented in figure 4). The first one is the vertical logo brand and same transparent logo from behind. Second AOI is the principal logo label in front of bottle and information label from behind. Third one is the bottle cap and the last is border/silhouette of bottle.

\section{RESULTS AND DISCUSSION}

All the statistical analyses have been performed with SPSS R17 and Tobii ${ }^{\circledR}$ Studio 3.2.1 software. This last application was used to visually understand participant overall behaviour regarding what part of the stimuli attracted their attention. Absolute duration parameter was selected to create heat maps presented in figure 5 that were used to identify AOIs. Red shades indicate the areas which presented an extended period of time fixation, while yellow and purple colour represented areas with lower values in this parameter.

\section{Analysis of semantic scales}

As shown in Table 1, bipolar semantic words were used to evaluate bottles. As noted previously, seven level scales were used to get participants' response. Due to the lack of normality in results, a Wilcoxon signed-rank test ${ }^{20}$ was used to compare participants' perception. Statistical analysis is reported in Table 2.

There were significant differences $(\mathrm{p}<.05)$ in 4 of 12 variables tested. In resolution axe there were no variables with differences. In novelty and emotional axes there were differences just in one of the three variables: antiquated/fashion $(Z=-2.489, \mathrm{p}=.013)$ and empathy/indifference $(Z=-2.433, \mathrm{p}=.015)$. Regarding style dimension there were differences in two variables: wrong-crafted/well-crafted $(Z=-4.65, p<.001)$ and durable/fragile $(\mathrm{Z}=-1.968, \mathrm{p}=.049)$

\section{Analysis of eye-tracking data}

Three variables were used to understand the participants' perception for real and virtual bottle comparison. Results for variable Visit Count are reported in Table 3. Visits counts showed similar results in Cap, Central Logo and Vertical Logo AOIs in all the frontal views. There were more differences in Border AOI. Regarding back view, there were more differences especially in information bottle and vertical transparent logo on back view, in cap in $60^{\circ}$ view and in border in all the views.

The second variable is Total Time Fixation (TTF). This variable describes the whole time spent in a particular AOI. This is one of the best indicators for analysing consumer attention. Due to the lack of normality in results, a Wilcoxon signed-rank test ${ }^{20}$ was used to compare TTFs between virtual and real bottles. Statistical analysis is reported in Table 4.

There were significant differences $(\mathrm{p}<.05)$ in 11 of 32 variables tested. Regarding frontal views, there were significant differences in $(\mathrm{p}<.05)$ in 4 of 16 variables: Central Logo at $0^{\circ}(Z=-2.357, p=.018)$, Central Logo at 
$35^{\circ}(\mathrm{Z}=-2.233, \mathrm{p}=.026)$, Central Logo at $60^{\circ}(\mathrm{Z}=-3.198, \mathrm{p}=.001)$ and Vertical Logo at $(\mathrm{Z}=-3.104, \mathrm{p}=.002)$. This fact is especially important, taking into account the information in Table 3 , which shows that Central Logo AOI got the highest number of visits. Concerning back view, there are significant differences in $(p<.05)$ in 8 of 16 variables. It is very relevant that in the Information Bottle AOI there were significant differences in 3 of 4 orientations: $0^{\circ}(Z=-5.373, p<.001), 35^{\circ}(Z=-3.082, p<.002)$ and $60^{\circ}(Z=-2.580, p=.01)$.

The third variable used was Time to First Fixation (TFF). It describes the exactly time when participant look at a specific AOI. This parameter can show the relevance of an explicit detail in stimulus; for this work this variable is essential to determinate similitude in perception, because if statistically are similar, the supposition of similarity is real.

There were also significant differences $(\mathrm{p}<.05)$ in 11 of 32 variables tested. Regarding frontal views, there were significant differences in $(\mathrm{p}<.05)$ in 3 of 16 variables: Central Logo at $0^{\circ}(Z=-5.004, p=<.001)$, Central Logo at $15^{\circ}(\mathrm{Z}=-4.579, \mathrm{p}=<.001)$, Central $\log 0$ at $35^{\circ}(\mathrm{Z}=-4.134, \mathrm{p}=<.001)$. As noted previously, this fact is especially important, taking into account that Central Logo AOI got the highest number of visits. Concerning back view, there are significant differences in $(\mathrm{p}<.05)$ in 9 of 16 variables. It is very relevant that in the Information Bottle AOI there were significant differences in all orientations: $0^{\circ}(Z=-3.644, p<.001), 15^{\circ}(Z=--$ $5.214, \mathrm{p}<.001), 35^{\circ}(\mathrm{Z}=-2.959, \mathrm{p}=.003)$ and $60^{\circ}(\mathrm{Z}=-3.161, \mathrm{p}=.002)$.

If we observe Figure 2 we can suggest some explanations for the obtained results. It is more accentuated the difference between back views comparing real and virtual representation. The rendered images do not capture the transparency and liquid levels in the same way that the images of the real bottle. Probably, this fact has influence in the perception, as it affects the visualization of some details. Regarding front views, the rendered images also show insufficient quality in the representation of transparency. Observing the images, the central logo receives more emphasis in the virtual representation than in the real one. Probably this unwanted effect provokes a different perception in participants.

\section{CONCLUSIONS}

Perception is affected by small details in stimuli as shown in the experimental study presented in this work. This fact must be carefully taken into account when conclusions must be obtained from virtual representations created by rendering systems. This really does not represent a problem when a series of static images must be generated to be used as stimuli. High quality photorealistic rendering techniques can provide images that are indistinguishable from the real objects. However, in the case of dynamic images, when it is very common to use a game engine to provide interaction with $3 \mathrm{D}$ virtual environments, this can be a serious limitation. This is the case when a study pretends obtain perceptual evaluations from users inside a virtual environment as a CAVE or are visualizing a 3D scene using HMD displays such as Oculus Rift. The stimuli presented in this study where created in order to obtain high frame rates when the bottles are located inside a virtual scene. The main conclusion is that a higher quality rendering engine must be used to achieve a higher fidelity representing the real objects that are going to be evaluated in the virtual space. The joint application of semantic scales and eye tracking provides a robust combination to identify differences in the perception of new product and packaging details. New development in game engines and the growing computational capability of new GPUs in graphics cards will avoid in the future, many of the problems that currently must be faced due to the trade-off between high frame rates and ultra-photorealistic image calculations.

\section{REFERENCES}

1. Underwood RL, Klein NM, Burke RR. Packaging communication: attentional effects of product imagery. Journal of Product \& Brand Management 2001; 10(7): 403-422.

2. Reutskaja E, Nagel R, Camerer CF, Rangel A. Search dynamics in consumer choice under time pressure: An eye-tracking study. The American Economic Review 2011; 101: 900-926.

3. Ares G, Barreiro C, Deliza R, Giménez A, Gámbaro A. Consumer expectations and perception of chocolate milk desserts enriched with antioxidants. Journal of Sensory Studies 2010; 25: 243-260.

4. Moskowitz HR, Reisner M, Lawlor JB, Deliza R. Packaging research in food product design and development. Ames: Wiley-Blackwell, 2009. 
5. Touhami ZO, Benlafkih L, Jiddane M, Cherrah Y, Malki HOEL, Benomar A. Neuromarketing: Where marketing and neuroscience meet. African Journal of Business Management 2011; 5(5): 1528-1532.

6. Chatterjee A. Neuroaesthetics: a coming of age story. Journal of cognitive neuroscience 2011; 23(1): 5362.

7. Pieters R, Warlop L. Visual attention during brand choice: The impact of time pressure and task motivation. International Journal of Research in Marketing 1999; 16(1):1-16.

8. Reimann M, Weber B, Bender T, Zaichkowsky J, Neuhaus C. Aesthetic package design: A behavioral, neural, and psychological investigation. Journal of Consumer Psychology 2010.

9. Hoffman J, Subramaniam B. The role of visual attention in saccadic eye movements. Perception \& Psychophysics 1995; 57: 787-795.

10. Spence C, Driver J. (Eds). Crossmodal space and crossmodal attention. Oxford: Oxford University Press 2004.

11. Piqueras-Fiszman B, Velasco C, Salgado-Montejo A, Spence C. Using combined eye tracking and word association in order to assess novel packaging solutions: A case study involving jam jars. Food Quality and Preference 2013; 28(1): 328-338.

12. Pertzob Y, Avidan G, Zohary E. Accumulation of visual information across multiple fixations. Journal of Vision 2009; 9: 1-12.

13. Djamasbi S, Siegel M, Tullis T. Generation Y, web design, and eye tracking. International Journal of Human-Computer Studies 2010: 68(5): 307-323.

14. Osgood CE, Suci GJ, Tannenbaum PH. The measurement of meaning. Urbana, IL: University of Illinois Press 1957.

15. Besemer S. Creative Product Analysis to Foster Innovation. Design Management Journal 2010; 11(4): 5964.

16. Rebollar R, Lidón I, Martín J, Puebla M. The identification of viewing patterns of chocolate snack packages using eye-tracking techniques. Food Quality \& Preference 2014.

17. Kessel LTE, Ruiter RAC. Eye movement responses to health messages on cigarette packages. BMC Public Health 2012; 12: 352.

18. Ledoux T, Nguyen AS, Bakos-Block C, Bordnick P. Using virtual reality to study food cravings. Appetite 2013; 71: 396-402.

19. Gomes T, Hurley RA, Duchowski A, Darby D, Ouzts A. The effect of full body versus partial body graphic labelling on beverage packaging. Packaging Technology and Science 2014; 27(12): 933-943.

20. Conover WJ. Practical Nonparametric Statistics, Third Edition, New York: John Wiley \& Sons 1999. 
TABLE 1. CPSS AND

\begin{tabular}{c|c|c|c}
\hline $\begin{array}{c}\text { NOVELTY } \\
\text { (novedad) }\end{array}$ & $\begin{array}{c}\text { RESOLUTION } \\
\text { (resolución) }\end{array}$ & $\begin{array}{c}\text { STYLE } \\
\text { (estilo) }\end{array}$ & $\begin{array}{c}\text { EMOTIONAL } \\
\text { (emocional) }\end{array}$ \\
\hline $\begin{array}{c}\text { Antiquated - Fashion } \\
\text { (anticuado - de moda) }\end{array}$ & $\begin{array}{c}\text { Female - Male } \\
\text { (femenino - masculino) }\end{array}$ & $\begin{array}{c}\text { Stable - Unstable } \\
\text { (estable - inestable) } \\
\text { Wrong-crafted - Well-crafted } \\
\text { (mal hecho - bien hecho) }\end{array}$ & $\begin{array}{c}\text { Euphoria - Tranquility } \\
\text { (euforia - tranquilidad) }\end{array}$ \\
$\begin{array}{c}\text { Usual - Unusual } \\
\text { (usual - inusual) }\end{array}$ & $\begin{array}{c}\text { Robust - Thin } \\
\text { (robusto - delgado) } \\
\text { (tristezs - - felicidad) }\end{array}$ \\
$\begin{array}{c}\text { Discreet - Revolutionary } \\
\text { (discreto - revolucionario) }\end{array}$ & $\begin{array}{c}\text { Tall - Short } \\
\text { (alto - bajo) }\end{array}$ & $\begin{array}{c}\text { Durable - fragile } \\
\text { (Durable - fragil) }\end{array}$ & $\begin{array}{c}\text { Empathy - indifference } \\
\text { (empatia - indiferencia) }\end{array}$ \\
\hline
\end{tabular}

EMOTIONAL AXIS USING IN

SEMANTIC EVALUATION. 
TABLE 2. RESULT FROM WILCOXON TEST AND RANKS EFFECTS.

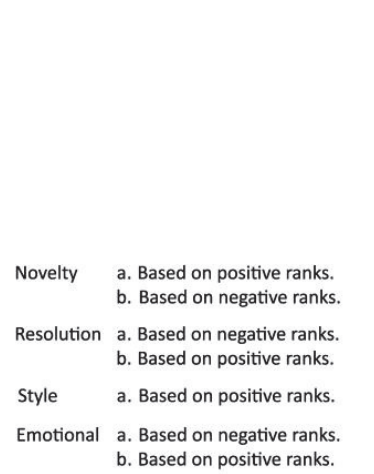

\begin{tabular}{llcc}
\hline \multirow{2}{*}{ NOVELTY } & \multicolumn{1}{c}{ Variable } & $Z$ & $P$ (Asymp. Sig) \\
\cline { 2 - 4 } & Antiquated/Fashion & $-2.489 \mathrm{a}$ & .013 \\
& Usual/Unusual & $-1.925 \mathrm{~b}$ & .054 \\
& Discreet/Revolutionary & $-.096 \mathrm{~b}$ & .924 \\
RESOLUTION & Female/Male & $-.783 \mathrm{a}$ & .433 \\
& Robust/Thin & $-1.318 \mathrm{~b}$ & .187 \\
Tall/Short & $-.357 \mathrm{~b}$ & .721 \\
STYLE & Stable/Unstable & $-.083 \mathrm{a}$ & .934 \\
& Wrong-crafted/Well-crafted & $-4.650 \mathrm{a}$ & .000 \\
& Durable/Fragile & $-1.968 \mathrm{a}$ & .049 \\
EMOTIONAL & Euphoria/Tranquility & $-.431 \mathrm{a}$ & .666 \\
& Sadness/Happiness & $-1.872 \mathrm{~b}$ & .061 \\
& Empathy/Indifference & $-2.433 \mathrm{a}$ & .015 \\
\hline
\end{tabular}


TABLE 3. MEAN RESULT FROM ALL

VISIT COUNT IN AOI REAL AND VIRTUAL BOTTLE.

\begin{tabular}{|c|c|c|c|c|c|c|c|c|}
\hline & \multicolumn{4}{|c|}{ Real Bottle } & \multicolumn{4}{|c|}{ Virtual Bottle } \\
\hline & Cap & Border & $\begin{array}{c}\text { Central } \\
\text { Logo }\end{array}$ & $\begin{array}{c}\text { Vertical } \\
\text { Logo }\end{array}$ & Cap & Border & $\begin{array}{c}\text { Central } \\
\text { Logo }\end{array}$ & $\begin{array}{c}\text { Vertical } \\
\text { Logo }\end{array}$ \\
\hline Frontal & 0 & 0.16 & 2.35 & 1.65 & 0.05 & 0.51 & 2.35 & 1.89 \\
\hline $15^{\circ}$ & 0.08 & 0.14 & 2.16 & 2.03 & 0.11 & 0.46 & 2.32 & 1.76 \\
\hline $35^{\circ}$ & 0.35 & 0.19 & 2.14 & 2.22 & 0.22 & 0.27 & 2.19 & 1.95 \\
\hline \multirow[t]{2}{*}{$60^{\circ}$} & 0.92 & 0.08 & 2.43 & 1.49 & 0.97 & 0.14 & 1.7 & 2.38 \\
\hline & Cap & Border & $\begin{array}{c}\text { Information } \\
\text { Bottle }\end{array}$ & $\begin{array}{l}\text { Vertical } \\
\text { transparent } \\
\text { Logo }\end{array}$ & Cap & Border & $\begin{array}{c}\text { Information } \\
\text { Bottle }\end{array}$ & $\begin{array}{l}\text { n Vertical } \\
\text { transparent } \\
\text { Logo }\end{array}$ \\
\hline Back & 0.03 & 0.24 & 2.38 & 1.92 & 0 & 0.03 & 0.08 & 0.05 \\
\hline $15^{\circ}$ & 0.11 & 0.16 & 2.43 & 2.38 & 0.11 & 0.32 & 2.43 & 1.62 \\
\hline $35^{\circ}$ & 0.41 & 0.14 & 2.73 & 1.41 & 0.22 & 0.24 & 1.89 & 1.46 \\
\hline $60^{\circ}$ & 0.86 & 0.03 & 1.08 & 0 & 1.62 & 0.11 & 1.89 & 0 \\
\hline
\end{tabular}


TABLE 4. RESULT FROM WILCOXON

\begin{tabular}{|c|c|c|c|c|c|c|}
\hline & Frontal & $z$ & P (Asymp. Sig) & Back & $z$ & P (Asymp. Sig) \\
\hline \multirow{4}{*}{$0^{\circ}$} & Cap & $-1.000^{\mathrm{a}}$ & .317 & Cap & $-1.089^{a}$ & .276 \\
\hline & Border & $-1.525^{a}$ & .127 & Border & $-2.264^{a}$ & .024 \\
\hline & Central Logo & $-2.357^{b}$ & .018 & $\begin{array}{c}\text { Information } \\
\text { Bottle }\end{array}$ & $-5.373^{b}$ & .000 \\
\hline & Vertical Logo & $-.173^{a}$ & .862 & $\begin{array}{c}\text { Vertical T. } \\
\text { Logo }\end{array}$ & $-4.488^{a}$ & .000 \\
\hline \multirow{4}{*}{$15^{\circ}$} & Cap & $-.593^{a}$ & .553 & Cap & $-.867^{a}$ & .386 \\
\hline & Border & $-1.731^{a}$ & .083 & Border & $-1.633^{a}$ & .102 \\
\hline & Central Logo & $-.581^{a}$ & .561 & $\begin{array}{l}\text { Information } \\
\text { Bottle }\end{array}$ & $-1.516^{a}$ & .130 \\
\hline & Vertical Logo & $-1.371^{b}$ & .171 & $\begin{array}{l}\text { Vertical T. } \\
\text { Logo }\end{array}$ & $-2.014^{b}$ & .044 \\
\hline \multirow{4}{*}{$35^{\circ}$} & Cap & $-1.095^{b}$ & .274 & Cap & $-1.285^{b}$ & .199 \\
\hline & Border & $-.458^{a}$ & .647 & Border & $-1.679^{a}$ & .093 \\
\hline & Central Logo & $-2.233^{a}$ & .026 & $\begin{array}{c}\text { Information } \\
\text { Bottle }\end{array}$ & $-3.082^{b}$ & .002 \\
\hline & Vertical Logo & $-1.471^{b}$ & .141 & $\begin{array}{l}\text { Vertical T. } \\
\text { Logo }\end{array}$ & $-.106^{a}$ & .915 \\
\hline \multirow{4}{*}{$60^{\circ}$} & Cap & $-1.795^{a}$ & .073 & Cap & $-3.161^{a}$ & .002 \\
\hline & Border & $-.983^{a}$ & .326 & Border & $-1.992^{a}$ & .046 \\
\hline & Central Logo & $-3.198^{b}$ & .001 & $\begin{array}{l}\text { Information } \\
\text { Bottle }\end{array}$ & $-2.580^{a}$ & .010 \\
\hline & Vertical Logo & $-3.104^{a}$ & .002 & $\begin{array}{c}\text { Vertical T. } \\
\text { Logo }\end{array}$ & $.000^{c}$ & 1.000 \\
\hline
\end{tabular}

a. Based on negative ranks.

b. Based on positive ranks.

c. The sum of negative ranks

ranks.

d. Wilcoxon Signed Ranks Test 


\begin{tabular}{|c|c|c|c|c|c|c|c|}
\hline $\begin{array}{l}\text { TABLE 5. RESULT FROM WILCOXON } \\
\text { TEST FOR TIME TO FIRST FIXATION. }\end{array}$ & & Frontal & $z$ & P (Asymp. Sig) & Back & $z$ & P (Asymp. Sig) \\
\hline & \multirow{4}{*}{$0^{\circ}$} & Cap & $-1.000^{\mathrm{a}}$ & .317 & Cap & $-.447^{b}$ & .655 \\
\hline & & Border & $-.283^{b}$ & .777 & Border & $-1.836^{b}$ & .066 \\
\hline & & Central Logo & $-5.004^{a}$ & .000 & $\begin{array}{c}\text { Information } \\
\text { Bottle }\end{array}$ & $-3.644^{b}$ & .000 \\
\hline & & Vertical Logo & $-.739^{a}$ & .460 & $\begin{array}{l}\text { Bottle } \\
\text { Vertical T. } \\
\text { Logo }\end{array}$ & $-3.874^{b}$ & .000 \\
\hline & \multirow{4}{*}{$15^{\circ}$} & Cap & $-.423^{\mathrm{a}}$ & .672 & Cap & $-.918^{b}$ & .359 \\
\hline & & Border & $-.675^{a}$ & .500 & Border & $-2.531^{\mathrm{a}}$ & .011 \\
\hline & & Central Logo & $-4.579^{a}$ & .000 & $\begin{array}{c}\text { Information } \\
\text { Bottle }\end{array}$ & $-5.214^{a}$ & .000 \\
\hline & & Vertical Logo & $-1.222^{a}$ & .222 & $\begin{array}{l}\text { Vertical T. } \\
\text { Logo }\end{array}$ & $-.729^{a}$ & .466 \\
\hline & \multirow{4}{*}{$35^{\circ}$} & Cap & $-1.873^{b}$ & .061 & Cap & $-2.330^{b}$ & .020 \\
\hline & & Border & $-.672^{b}$ & .501 & Border & $-1.786^{a}$ & .074 \\
\hline & & Central Logo & $-4.134^{a}$ & .000 & $\begin{array}{l}\text { Information } \\
\text { Bottle }\end{array}$ & $-2.959^{\mathrm{a}}$ & .003 \\
\hline & & Vertical Logo & $-1.948^{\mathrm{a}}$ & .051 & $\begin{array}{l}\text { Vertical T. } \\
\text { Logo }\end{array}$ & $-1.359^{b}$ & .174 \\
\hline & \multirow{4}{*}{$60^{\circ}$} & Cap & $-1.000^{a}$ & .317 & Cap & $-2.086^{a}$ & .037 \\
\hline & & Border & $-1.000^{b}$ & .317 & Border & $-1.992^{\mathrm{a}}$ & .046 \\
\hline a. Based on negative ranks. & & Central Logo & $-1.000^{b}$ & .317 & $\begin{array}{c}\text { Information } \\
\text { Bottle }\end{array}$ & $-3.161^{a}$ & .002 \\
\hline $\begin{array}{l}\text { b. Based on positive ranks. } \\
\text { c. Wilcoxon Signed Ranks Test }\end{array}$ & & Vertical Logo & $-1.000^{b}$ & .317 & $\begin{array}{l}\text { Vertical T. } \\
\text { Logo }\end{array}$ & $-1.342^{a}$ & .180 \\
\hline
\end{tabular}




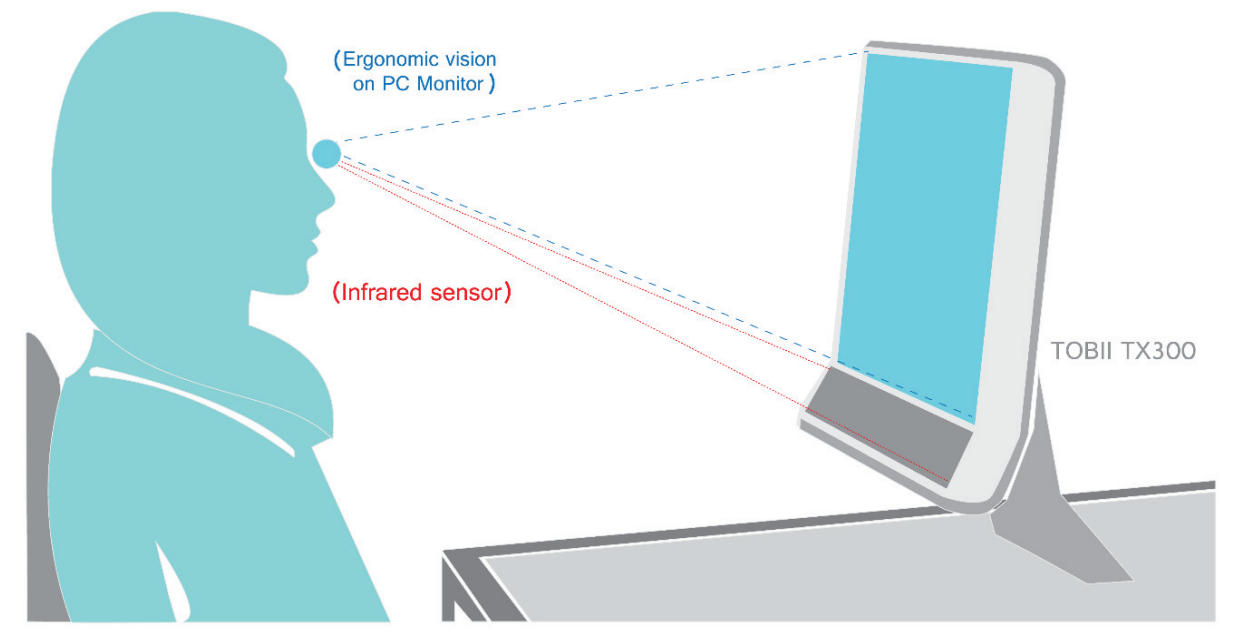

Figure 1. Eye tracking setup 


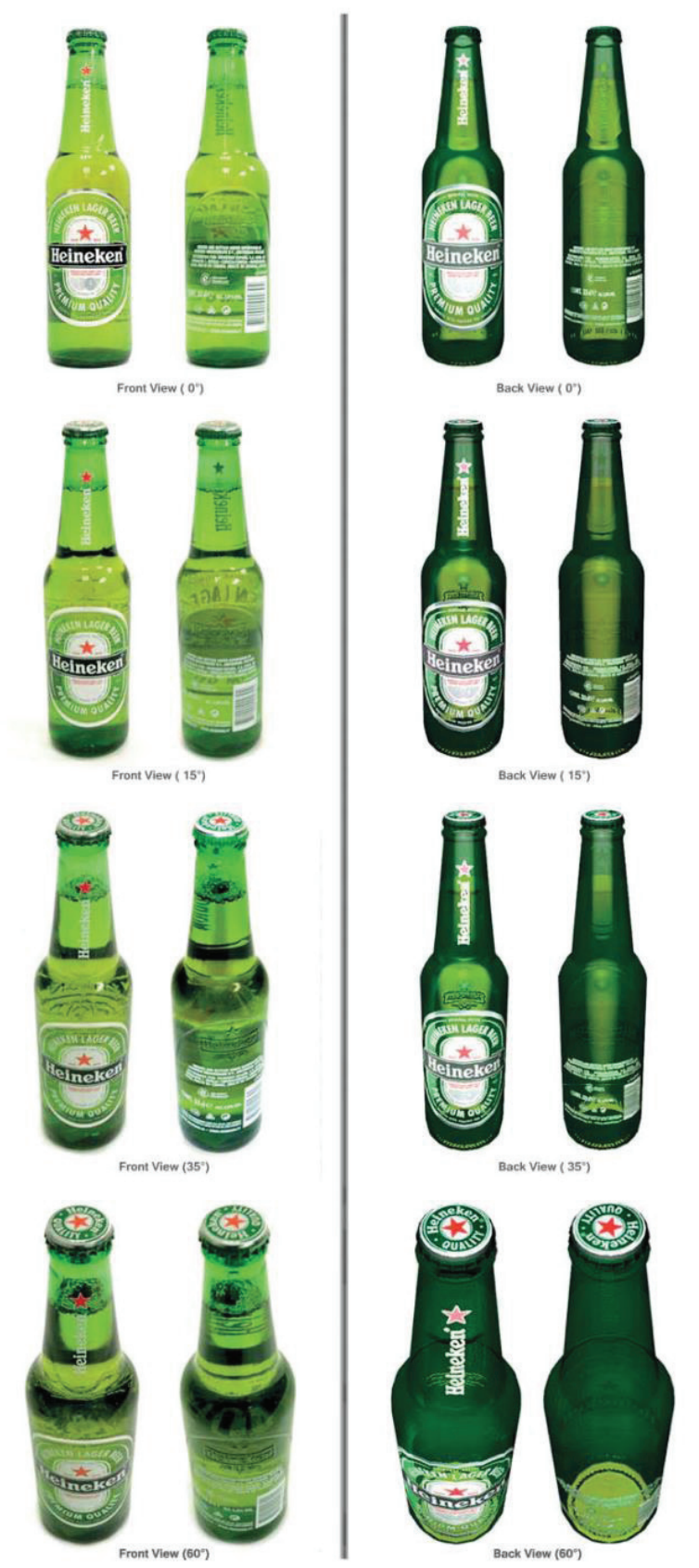

Figure 2. Real (left) and virtual (right) bottles images 


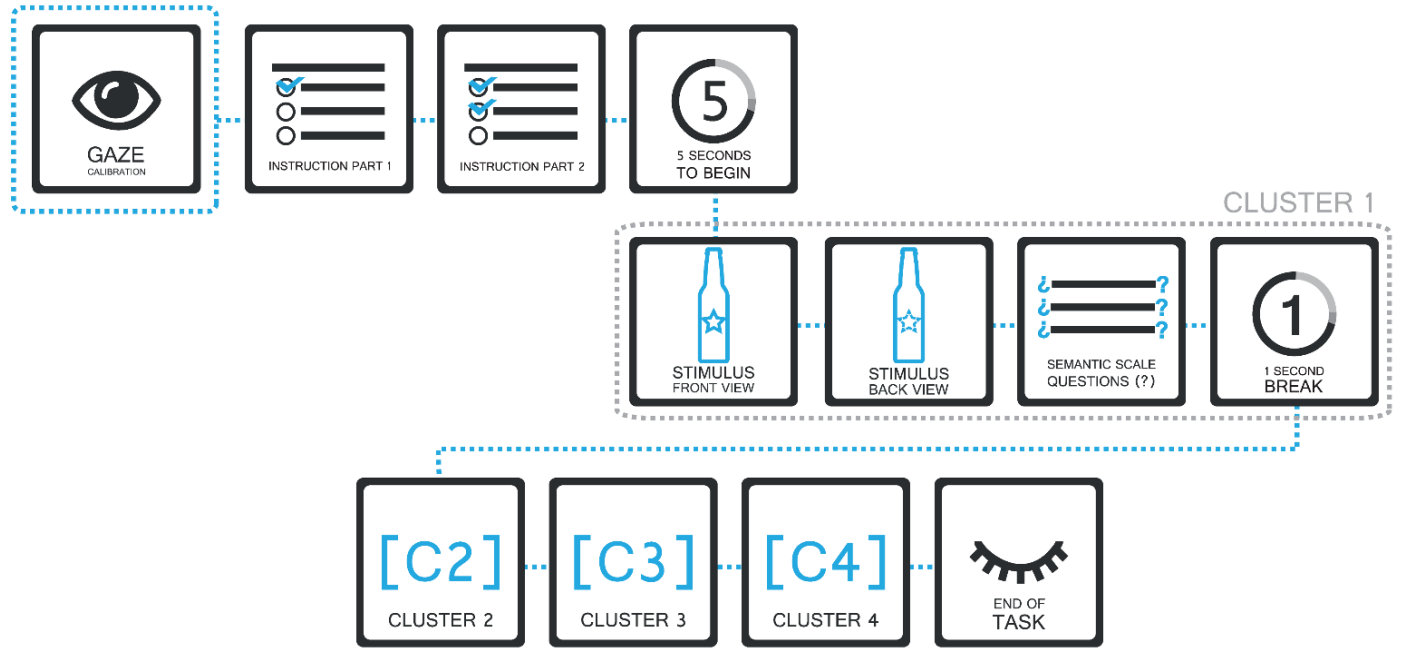

Figure 3. Task description 


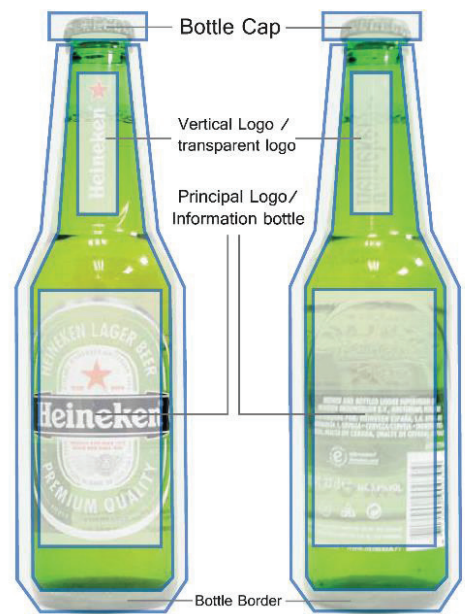

Figure 4. Areas of interest (AOI) in bottles 


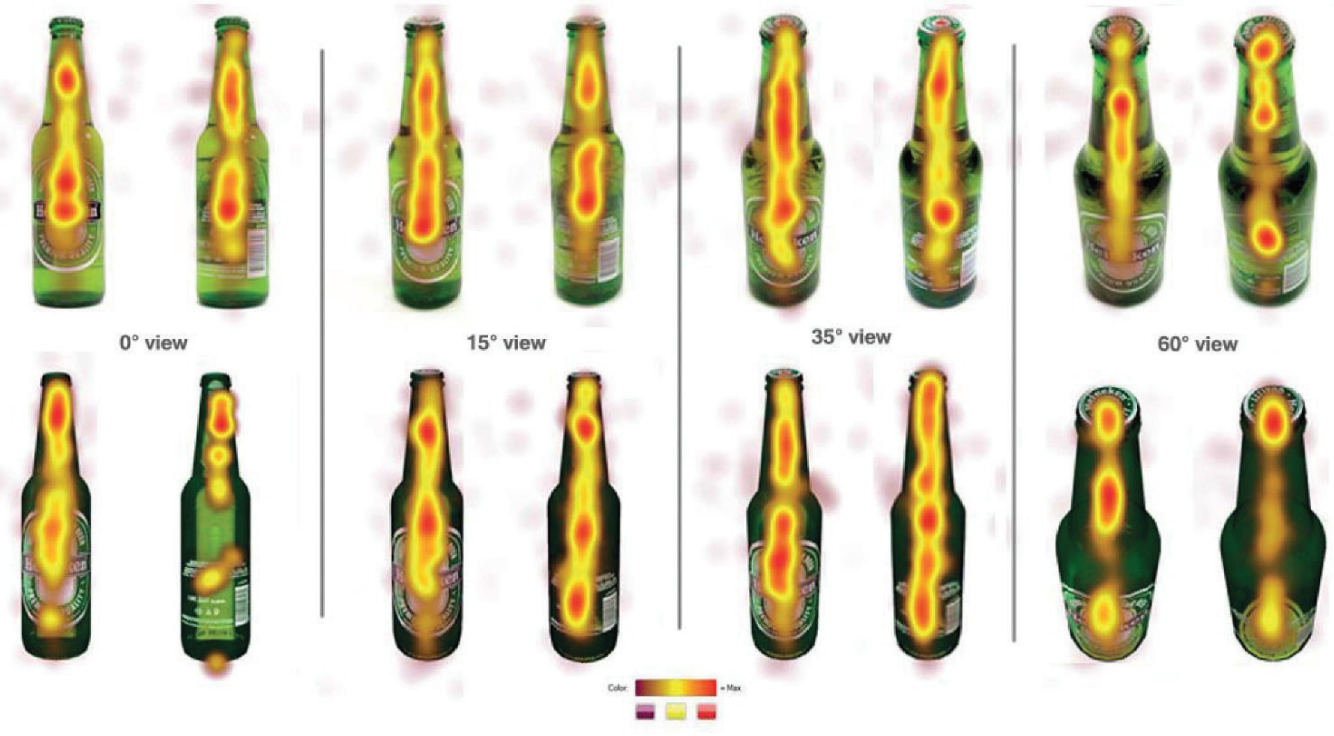

Figure 5. Heat maps 